\title{
REVIEW \\ Need for a comprehensive epidemiologic study of spinal cord injury in Poland: findings from a systematic review
}

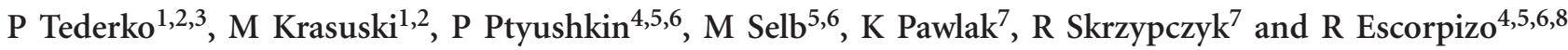

\begin{abstract}
Study design: Systematic literature review
Objective: To review and assess the quality of available epidemiologic data of spinal cord injury (SCI) in Poland in the context of general International Classification of Functioning (ICF) domains and to answer the question whether there is a need for a comprehensive epidemiologic study of $\mathrm{SCl}$ in Poland.

Methods: Databases Medline, Embase and Polish Medical Bibliography were searched using keywords 'spinal cord injury', 'paraplegia', 'tetraplegia' and 'Poland'. Inclusion criteria: studies on humans, original papers, publication in 1979 or later. Case reports and studies with unclear inclusion criteria or performed on a population other than Polish were excluded. Full texts were reviewed for data on incidence, prevalence, etiology, mortality, natural history and outcome of comprehensive treatment. Quality of studies was assessed according to the modified Downs and Black criteria. The ICF model was applied to group the studies according to the ICF components.
\end{abstract}

Results: Out of 536 identified papers, 224 articles were extracted and reviewed. Mean quality score was 11.04 points based on a 28 -grade scale. Body functions and structures were assessed in $81.6 \%$, activities in $22.4 \%$, participation in $14.8 \%$, environmental factors in $15.2 \%$ and personal factors in $47 \%$ of the studies reviewed.

Conclusion: Current epidemiologic data on $\mathrm{SCl}$ in Poland are insufficient and biased toward biomedical aspects. There is a need to develop a long-term research strategy for $\mathrm{SCl}$ in Poland in the form of a comprehensive cohort study.

Spinal Cord (2013) 51, 802-808; doi:10.1038/sc.2013.105; published online 17 September 2013

Keywords: spinal cord injury; Poland; paraplegia; tetraplegia

\section{INTRODUCTION}

Many people with disabilities worldwide, including those in Poland, do not have equal access to health care, education, employment and experience exclusion from activities of everyday life. ${ }^{1}$ On 6 September 2012, Poland ratified the United Nations Convention on the Rights of Persons with Disabilities (UNCRPD), which aims to ensure the equality of rights and opportunities for persons with disabilities. ${ }^{2}$

Disability associated with spinal cord injury (SCI) is serious and can last a lifetime. All organs and systems below the level of lesion can be affected. In addition to the loss of sensory and somatic functions, a wide range of other functional and structural problems is observed in individuals with SCI. These may include cardiovascular and respiratory problems, spasticity, neurogenic bladder and bowel, sexual dysfunction and neurogenic pain. SCI also increases the risk of respiratory and urinary complications, pressure sores, gastrointestinal bleeding, osteoporosis, male infertility, diabetes mellitus, ischemic heart disease, depression and suicide. SCI affects health-related quality of life and is associated with increased preterm mortality. ${ }^{3-18}$ Health and social care expenditure related to SCI varies according to severity of injury, but is generally high. Inpatient rehabilitation appears to be the most expensive part of health care provided to SCI person. ${ }^{19,20}$ Because of the complex physical, mental and social consequences of
SCI it can be regarded as an ideal case in point for implementation and monitoring of UNCRPD.

Health and social care for SCI in Poland has generally followed worldwide trend. ${ }^{21,22}$ It includes acute, post-acute and long-term care. The first and the main spinal centre in Poland is the Metropolitan Centre of Rehabilitation (STOCER) in Konstancin. Situated in central-eastern Poland provides acute, sub-acute and chronic care for SCI patients in the entire country, but mainly from central-eastern provinces with a population of 7.5 million. The average number of yearly admissions of new SCI cases was 139 (from 1965-1989) and increased to 220 in the early 1990s. The spinal unit has 45 beds and admits patients in the first hours after injury and providing comprehensive treatment. ${ }^{23}$ The second major rehabilitation centre for SCI is the Upper Silesian Rehabilitation Centre Repty in Tarnowskie Gory providing comprehensive rehabilitation for patients. ${ }^{24}$ The hospital has two SCI departments with 50 beds each and admits patients with SCI from all over the country, but mostly from southern and central Poland with a population of 13 million inhabitants. Particularly from southern and central areas of Poland with a population of 13 million inhabitants. The Upper Silesian Rehabilitation Centre accepts an average of 391 patients per year (including patients admitted for long-term care). In general, the

${ }^{1}$ Department of Rehabilitation, Medical University of Warsaw, Warszawa, Poland; ${ }^{2}$ Carolina Medical Center, Warsaw, Poland; ${ }^{3}$ College of Rehabilitation, Warsaw, Poland ${ }^{4}$ Department of Health Sciences and Health Policy, University of Lucerne and SPF, Nottwil, Switzerland; ${ }^{5}$ Swiss Paraplegic Research, Nottwil, Switzerland; ${ }^{9}$ ICF Research Branch in cooperation with the WHO Collaborating Centre for the Family of International Classifications in Germany (at DIMDI), Nottwil, Switzerland; ${ }^{7}$ Foundation for Active Rehabilitation, Warsaw, Poland and ${ }^{8}$ Department of Physical Therapy, Louisiana State University Health Sciences Center, New Orleans, LA, USA Correspondence: Dr P Tederko, Department of Rehabilitation, Medical University of Warsaw, Pory 78, 02-757 Warszawa, Poland. E-mail: p.tederko@gmail.com

Received 18 April 2013; revised 4 July 2013; accepted 6 August 2013; published online 17 September 2013 
central-eastern and southern parts of the country have better coverage with specialized institutions providing SCI acute and post-acute care. Persons injured in other areas have usually been transported by air to the spinal centers mentioned above or treated in local hospitals under the supervision of specialists from STOCER. Long-term care, social and vocational rehabilitation for persons with SCI in Poland is provided by multiple government and non-governmental organizations including the State Fund for Rehabilitation of the Disabled (PFRON), District Employment Agencies, Regional Social Assistance Centers, Career Initiative Companies and District Family Support Centres. ${ }^{25}$ Foundation for Active Rehabilitation (FAR) is currently the leader in non-governmental organizations providing long-term care for persons with SCI. The programme developed by FAR consists of recruitment, learning practical skills and follow-up. Rehabilitation instructors who are wheelchair users themselves visit hospitals and rehabilitation institutions encouraging patients with SCI to join the program. During the first-level training participants acquire practical skills and receive additional practical information for the future. Further assistance is provided by regional FAR offices located in all over the country. ${ }^{26}$

The improvement of the current situation with SCI care and policies in Poland depends, among other things, on the quality of corresponding epidemiologic data. These data are necessary for informing health and social policy makers, to modify the existing interventions and propose new ones, to optimize the distributions of resources, to implement and evaluate interventions and the use of assistive technologies. These data should include an updated incidence, prevalence, etiology and characteristics of SCI, description of functioning level and use of rehabilitation resources. It should cover not only disease-related characteristics of affected people, but also the positive and negative influences of environmental and personal factors. ${ }^{27}$ These data would be the starting point for implementation of the UNCRPD with regard to persons with SCI.

Many studies in Poland have focused on particular aspects of SCI epidemiology. However, there are currently no studies that look at SCI from a comprehensive perspective or summarize the available evidence for the country. The data are dispersed throughout a variety of articles and are often outdated. It is, therefore, not known whether the available data is sufficient and reliable to address the purposes mentioned in the previous paragraph.

Therefore, the objective of our paper is to summarize available epidemiologic data on SCI in Poland and to answer the question whether there is a need for a comprehensive epidemiologic study of SCI in Poland. To do this we had two specific aims: to identify the available epidemiologic data on SCI in Poland and to critically review this data to identify the possible gaps.

\section{MATERIALS AND METHODS}

\section{Study design}

Systematic literature review. The literature review aimed to retrieve the available epidemiologic data regarding SCI in Poland. To identify the relevant publications different combinations of the following keywords were used: spinal cord, injury, paraplegia, tetraplegia, Poland. They were searched using Medline, Embase databases and the Polish equivalent, Polish Medical Bibliography.

\section{Inclusion criteria}

Studies on humans, subject recruitment limited to persons with SCI, publication from 1979 to the present. The year 1979 was chosen because the main Polish medical database, Polish Medical Bibliography, has been systematically registering data from 1979 on. Case reports, studies with unclear patient entry criteria or on a population other than Polish were excluded. Abstracts were first screened for satisfaction of the inclusion criteria. Full texts of the relevant articles were then reviewed examining original data on incidence, prevalence and etiology, mortality, natural history, outcome of comprehensive treatment that also included addressing body structures and functions, activities and participation and contextual factors.

Methodological quality was evaluated with the modified Downs and Black scoring system..$^{28}$ The last question of study power was simplified. The original response scale from 0 to 5 was replaced by a scale of 0 to 1 , where 1 was scored if a power calculation or sample size calculation was present, whereas 0 was scored if there was no power calculation. This modification has been previously used in SCI studies, such as Canadian project Spinal Cord Injury Rehabilitation Evidence (SCIRE). ${ }^{29}$ The total score in the modified version ranged from 0 to 28 , with a higher score indicating higher methodological quality. The quality score was assessed independently by two of this article's authors (PT and MK). Extracted data comprised quality of reporting (10 items), external validity ( 3 items), internal validity ( 13 items including bias -7 items and confounding -6 items) and power ( 1 item). Any differences in results, which were due mostly to reading errors, were resolved by discussion between the two authors.

\section{Presentation of the results}

The International Classification of Functioning, Disability and Health (ICF) model was used to group the studies according to its components. According to the ICF, human functioning is understood as an interaction between a health condition, body functions and body structures, activities and participation and contextual (environmental and personal) factors. ${ }^{30}$ Results presented below come from pooling of relevant data acquired from studies using similar methodology.

\section{RESULTS}

Overall 536 papers were identified. Of them, 312 were excluded as not fulfilling inclusion criteria. A total of 224 articles were extracted and reviewed. Complete list of analyzed papers is available from a supplementary data file referring to this article. Of the papers we reviewed, 109 (48.7\%) papers came from Kiwerski et al. from STOCER Rehabilitation Center. Out of this number, 89 papers provided coherent data of acute and post-acute period of SCI management. These papers provided data of SCI etiology, localization, applied therapeutic modes and outcomes based on $\sim 4000$ SCI cases admitted on the first day after injury between 1965 and 1993. Figure 1 presents the number of papers on SCI in Poland published in consecutive 5 -year periods.

\section{Study quality}

The mean for the modified Downs and Black score for the 224 papers was 11.04 (s.d. $=3.68$ ) points. Average score percentages in Downs and Black subscales were for reporting: 4.74, for external validity: 2.34, for bias: 2.87 , and for confounding 1.22. No studies had power

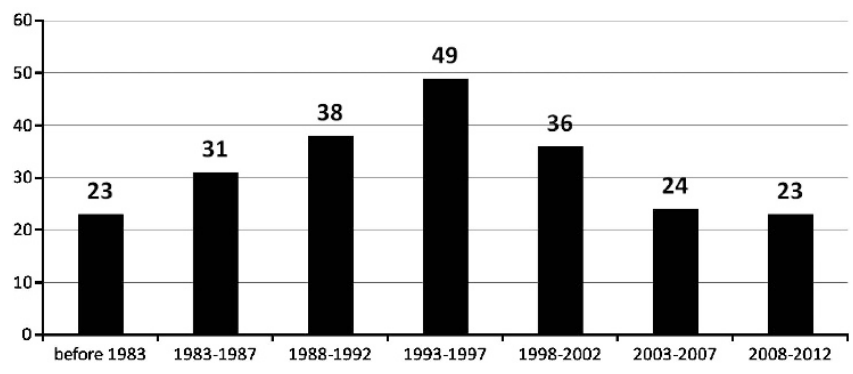

Figure 1 Number of papers on $\mathrm{SCl}$ in Poland published in consecutive time periods. 
or sample size calculation. The detailed results of quality assessment using the modified Downs and Black is lengthy, hence it was not included here. A copy can be requested from the first author.

\section{Study design}

There were 161 retrospective and 63 prospective studies. The number of subjects included in individual studies ranged from 3 to 3672 (mean 336.3). Seven studies $(3.1 \%)$ were multicenter trials (patients recruited from at least two centers). Additional inclusion criteria included injury location and time elapsed since injury. Other inclusion criteria varied between studies but included therapeutic variables or outcome related variables (for example, specific complications of the injury or its treatment). A total of 173 studies $(77.6 \%)$ were based in a hospital setting (mean number of participants $=390.8)$, whereas 45 studies $(20.2 \%)$ involved patients living in their usual environment (mean number of participants $=$ 135.6). Two studies were based on autopsy data.

\section{Incidence and prevalence of SCI}

Two studies specifically aimed at identification of the incidence of SCI in Poland. Based on the analysis of 1374 hospital records from western Poland, Lubuskie province (2005-2008) estimated the incidence of SCI in the region to be 14.5 new cases per 1 million people. Case identification was based on International Statistical Classification of Diseases and Related Health Problems 10th Revision (ICD-10) codes S12-S34 and T08, T09, T91 with exclusion of codes not related to the spine. ${ }^{31}$ According to Haftek et al. ${ }^{32}$ from STOCER, among 78 new cases of SCI admitted to STOCER in a half-year period (AprilSeptember 1999), 52 came from Mazovian Province (population of 5.2 million). Assuming that STOCER served as the only SCI reference centre in the Province, the authors estimated an annual incidence rate of 20 new cases per million. The trial could be biased by preadmission mortality, unknown number of cases transferred to trauma centers outside Mazovian Province, and potential nonrepresentativeness of a summer season versus all-year incidence rates. Based on the data from STOCER, $60.6 \%$ of injuries occurred in the third quarter of the year (summer-autumn period). ${ }^{23}$ Females with paraplegia appeared six times less frequently compared with males. ${ }^{33}$ Studies citing gender differences referred only to persons with paraplegia. Comparison of epidemiologic data from 1965 to 1970 and 1985 to 1990 revealed a rise of young patients with multiple injury among those admitted with acute cervical SCI. The rate of patients below 20 years of age increased from $16 \%$ to $20 \%$. Proportion of persons with multiple injury grew from $7 \%$ to $15 \% .{ }^{34}$ We identified no studies investigating the prevalence of SCI in Poland.

\section{Causes of SCI}

Figures given below come from pooling of relevant data acquired from studies using similar methodology. Based on the data coming from STOCER, most frequent causes of SCI regardless of injury level were falls from a horse cart $(24.3 \%)$ followed by other traffic accidents $(24.5 \%)$ and diving $(19.8 \%)$. Victims of horse cart falls were usually older individuals (53.5\% over 60 years of age), whereas diving injury was typical for young men (62\% of those under 20 years of age). Among patients admitted to STOCER between 1965 and 1981 in the acute phase of cervical SCI, C1-C4 injuries usually resulted from falls from a height $(70 \%)$, diving (12\%) and traffic accidents $23 \%$. SCI in children and adolescents resulted usually from diving (38\%), falls from a height (30\%) and traffic accidents (21\%). Persons over 60 years of age admitted to STOCER with cervical SCI came predominantly from the rural areas, and fall from a height was the cause of injury in $78.7 \%$ of cases. Typical mechanism of spinal injury in this group was cervical hyperflexion (44.1\%), followed by hyperextension (33\%). Dislocation was observed in $30.1 \%$. For all SCI, the most common injury mechanisms included hyperflexion (48\% out of this number, 35\% with dislocation), hyperextension (26\%) and compression fracture $(26 \%) .^{23,34-36}$

A comparison of the causes of cervical injuries between 1965 and 1970 and 1985 and 1990 revealed a significant increase in injuries caused by traffic accidents (from $12 \%$ to $30 \%$ with a particular rise in automobile accidents from $6 \%$ to $18 \%$ ) and a significant decrease of injuries due to falls from a horse cart (from $35 \%$ to $17 \%$ ). ${ }^{34}$

\section{Mortality from SCI}

In persons with SCI admitted to STOCER, a total mortality rate in the acute phase was $8.9 \%$. Mortality depended on injury localization (occurred in $18 \%$ of cervical, $7.5 \%$ of thoracic and $2.4 \%$ of lumbar SCI). Mortality predictors included severity of neurological deficit, etiology of injury and age. Mortality in patients with Frankel A grade on admission was $17.9 \%$. Among the causes of injury resulting in the highest rate of acute phase mortality were falls from scaffolding (21\%), from a horse cart $(20 \%)$ or from a roof (19\%). Injuries sustained by pedestrians struck by motor vehicles resulted in $16 \%$ of mortality. ${ }^{37}$ The mortality rate increased markedly in patients over the age of 40 years, and was higher nearly tenfold in individuals over 60 years of age compared with persons under 20 years. Even in the youngest group with a complete deficit at the cervical level, the mortality reached nearly $10 \%$ and gradually increased with age to over $60 \%$ in those aged over 60 years who had been admitted with a complete cervical lesion. The leading cause of death was pneumonia (52\%). Pulmonary complications accounted for $74 \%$ of total deaths. In that group, $13 \%$ of deaths resulted from primary respiratory insufficiency, usually due to the high level of the complete neural deficit. Following primary respiratory insufficiency, was death from abdominal complications such as bleeding from the gastrointestinal tract $(8 \%)$, urosepsis $(7.4 \%)$, pulmonary embolism $(6.2 \%)$ and irreversible brain injury $(6 \%)$ were the most relevant causes of death following SCI. The average length of time from onset of SCI until death was 26.3 days. ${ }^{38}$ In all, $73 \%$ of deaths in persons with high cervical injuries occurred in the first 3 weeks and were also related to pulmonary complications. ${ }^{39}$ Mortality in persons older than 75 years was up to $41 \% .^{36}$

\section{Outcomes in terms of the ICF domains}

The distribution of studies according to the components of the ICF model is shown in Figure 2.

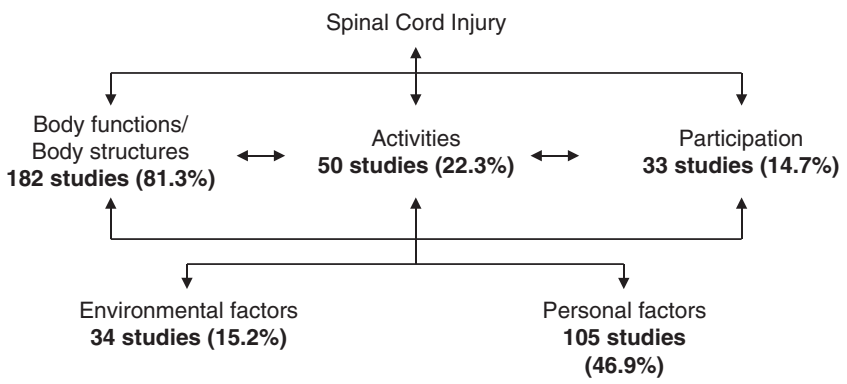

Figure 2 Distribution of the 224 identified studies on SCl in Poland according to components of the ICF. Arrows illustrate interactions between the different components of functioning and contextual factors. 
Body structures and body functions were assessed in 182 papers $(81.6 \%)$ (Table 1). Musculoskeletal and neural imaging were applied in 104 studies. In 98 papers, functions of the nervous system were described according to international standards for neurological classification of SCI, or Konstancin scale- a functional and neurological classification widely applied in Poland since 1964 and is practically identical with the Frankel scale. ${ }^{40}$ The Benzel Larson scale was applied in two studies. In 32 papers, the neurological classification used to describe deficits was unclear or poorly described. Instrumental (neurophysiological) tools such as electromyography, motor and somatosensory evoked potentials were applied in three studies. Heart rate variability as a tool for assessing autonomic nervous function was applied in three studies. Spirometric parameters were evaluated in five studies. Specific tools of functional assessment, including Ashworth or modified Ashworth scales in spasticity assessment, were used in two studies. Laboratory tests to assess

Table 1 Areas of "body functions" and 'body structures', which were assessed in the studies

\begin{tabular}{ll}
\hline $\begin{array}{l}\text { Function/ } \\
\text { structure }\end{array}$ & Tools used for assessment-number \\
assessed & of studies given in brackets
\end{tabular}

Motor function 135 papers (60.2\%) Konstancin scale, Frankel scale or ASIA Impairment scale (98), neurophysiological electrodiagnostic tools (3) Benzel Larson scale (2), poorly described (32)

Spasticity $\quad 2$ papers $(0.9 \%)$

Respiratory 7 papers $(3.1 \%)$

Upper limb 6 papers $(2.7 \%)$

Cardiovascular 3 papers $(1.3 \%)$

Urological 13 papers $(5.8 \%)$

Sensory $\quad 7$ papers $(3.1 \%)$

Pain

4 papers $(1.8 \%)$

Mental

5 papers $(2.2 \%)$

Endocrine

1 paper $(0.4 \%)$

Sexual

1 paper $(0.4 \%)$

Fertility $\quad 1$ paper $(0.4 \%)$

Skin 4 papers $(1.8 \%)$

Vestibular $\quad 1$ paper $(0.4 \%)$

Sleep 1 paper $(0.4 \%)$

Spine and 104 papers (46.4\%)

spinal cord

Motivation 2 papers $(0.9 \%)$

Orientation $\quad 3$ papers $(1.3 \%)$

to self function of central nervous system such as malondialdehyde concentration and conjugated diens in erytrocytes and plasma, creatine phosphokinase, lactate dehydrogenase, hydroxybutyrate dehydrogenase were analyzed in three trials.

Among tools applied for anxiety and depression assessment, Beck inventory was used in one study, while Hospital Anxiety and Depression scale was applied in four studies. Mell Krat scale and Male Sexual Pathology scale for assessment of sexual functions were used in one study. Penile vibratory test and laboratory sperm examination to assess reproductive functions was performed in one study. One study involved the analysis of microbiological samples collected from SCI individuals.

Upper limb function was addressed in six trials. Other body functions parameters measured in the studies included respiratory function, cardiovascular functions, urological function, sensation, pain, spasticity, anxiety and depression, endocrine functions, functions of the skin, equilibrium, sleep and tiredness.

Activities and participation were evaluated in 67 papers (29.9\%). Walking was assessed in 19 papers, moving using a wheelchair was analyzed in 8 publications, toileting in 11 papers. Twenty-four papers involved a simplified Konstancin index of mobility, whereas the independence inventory developed by (FAR) was used in six papers. A modified Rankin scale was used in one study, Barthel index or its expanded version known as Repty scale was used in four trials. Moving using a wheelchair was assessed using Wheelchair Skill Test 2.4 in two trials, whereas Ride Technique Test was applied in three studies. Employment was evaluated in 19 papers. Participation in selected social activities (programs offered by non-government organizations and involvement in sports and physical recreation) was studied in 12 papers. There was also one study aimed at assessing participation of persons with SCI in cultural activities (Table 2). In the largest community-based study comprising of 1034 persons who were interviewed between 2004 and 2005, a relationship between practicing of a favorite sport (especially team sports), higher levels of athletic identity and better psychological adjustment was identified. In ten papers, authors applied study-specific tools for activity

Table 2 Areas of 'activities' and 'participation', which were assessed in the studies

\begin{tabular}{|c|c|c|}
\hline $\begin{array}{l}\text { Activity or } \\
\text { parcticpation } \\
\text { assessed }\end{array}$ & Frequency & $\begin{array}{l}\text { Tools used for assessment-number } \\
\text { of studies given in brackets }\end{array}$ \\
\hline Walking & 19 papers $(8.5 \%)$ & $\begin{array}{l}\text { Konstancin walking scale (13), Foundation } \\
\text { of Active Rehabilitation Walking scale (1), } \\
\text { Repty index (1), study-specific non-stan- } \\
\text { dardized tools (4) }\end{array}$ \\
\hline $\begin{array}{l}\text { Moving on a } \\
\text { wheelchair }\end{array}$ & 8 papers $(3.6 \%)$ & $\begin{array}{l}\text { Ride Technique Test (3), Wheelchair Skill } \\
\text { Test } 2.4 \text { (2), study-specific non-standar- } \\
\text { dized tools (3) }\end{array}$ \\
\hline Toiletting & 11 papers $(4.9 \%)$ & $\begin{array}{l}\text { Foundation of Active Rehabilitation Inde- } \\
\text { pendence Inventory (6), modified Barthel } \\
\text { Index (2), Konstancin Independence scale } \\
\text { (2), study-specific non-standardized tool (1) }\end{array}$ \\
\hline Employment & 19 papers $(8.5 \%)$ & Study-specific non-standardized tools \\
\hline Social & 9 papers $(4 \%)$ & Study-specific non-standardized tools \\
\hline $\begin{array}{l}\text { Sport and } \\
\text { recreation }\end{array}$ & 14 papers $(6.3 \%)$ & Study specific non-standardized tools \\
\hline Cultural & 1 paper $(0.4 \%)$ & Study-specific non-standardized tools \\
\hline
\end{tabular}


Table 3 Areas of 'environmental factors' that were assessed in the studies

\begin{tabular}{|c|c|c|}
\hline $\begin{array}{l}\text { Environmental } \\
\text { factor }\end{array}$ & Frequency & $\begin{array}{l}\text { Tools used for assessment-number } \\
\text { of studies given in brackets }\end{array}$ \\
\hline Housing & 17 papers $(7.6 \%)$ & Study-specific non-standardized tools \\
\hline Income & 9 papers $(4 \%)$ & Study-specific non-standardized tools \\
\hline Nutrition & 1 paper $(0.4 \%)$ & $\begin{array}{l}\text { Starzynski Questionnaire, Bielinska } \\
\text { Questionnaire modified by Kulesza }\end{array}$ \\
\hline Health services & 9 papers $(4 \%)$ & Study-specific non-standardized tools \\
\hline $\begin{array}{l}\text { Assistive } \\
\text { technologies }\end{array}$ & 6 papers $(2.6 \%)$ & Study-specific non-standardized tools \\
\hline Family & 7 papers $(3.1 \%)$ & $\begin{array}{l}\text { California Psychological Inventory (1), } \\
\text { study specific }\end{array}$ \\
\hline Friends & 3 papers $(1.3 \%)$ & $\begin{array}{l}\text { California Psychological Inventory (1), } \\
\text { study specific }\end{array}$ \\
\hline Attitudes & 5 papers $(2.2 \%)$ & Study-specific non-standardized tools \\
\hline Legal & 3 papers $(1.3 \%)$ & Study-specific non-standardized tools \\
\hline
\end{tabular}

Table 4 Areas of 'personal factors' that were assessed in the studies

\begin{tabular}{|c|c|c|}
\hline $\begin{array}{l}\text { Personal } \\
\text { factor }\end{array}$ & Frequency & $\begin{array}{l}\text { Tools used for assessment-number } \\
\text { of studies given in brackets }\end{array}$ \\
\hline Age & 102 papers $(45.5 \%)$ & Demographic questionnaires \\
\hline Gender & 50 papers $(22.3 \%)$ & \\
\hline Education & 16 papers $(7.1 \%)$ & \\
\hline Lifestyle & 6 papers $(2.6 \%)$ & $\begin{array}{l}\text { Situational Preference Inventory } \\
\text { (Edwars) (1), Pack years of smoking (2), } \\
\text { study specific }\end{array}$ \\
\hline $\begin{array}{l}\text { Health and } \\
\text { legal } \\
\text { awareness }\end{array}$ & 5 papers $(2.2 \%)$ & Study-specific non-standardized tools \\
\hline $\begin{array}{l}\text { Personality } \\
\text { traits }\end{array}$ & 5 papers $(2.2 \%)$ & $\begin{array}{l}\text { Eysenck Inventory (2), Adjective Checklist } \\
\text { (Gough, Heilburn) (1), Study-specific } \\
\text { non-standardized tools ( } 2 \text { ) }\end{array}$ \\
\hline $\begin{array}{l}\text { Coping } \\
\text { strategies }\end{array}$ & 3 papers $(1.3 \%)$ & $\begin{array}{l}\text { Psychosocial Questionnaire for Spinal Cord } \\
\text { Injured Persons, Psychological Adjustment } \\
\text { to Chronic Illness (Shontz, Fink), Situational } \\
\text { Preference Inventory (1), Neuroliguistic Test } \\
\text { of Problem Solving (1), Study-specific } \\
\text { non-standardized tool (1) }\end{array}$ \\
\hline Life purpose & 2 papers $(0.9 \%)$ & $\begin{array}{l}\text { Purpose in Life Test (Crumbaugh, Macholik) } \\
\text { (1), Study-specific non-standardized tool (1) }\end{array}$ \\
\hline $\begin{array}{l}\text { Athletic } \\
\text { identity }\end{array}$ & 2 papers $(0.9 \%)$ & $\begin{array}{l}\text { Athletic Identity Measurement scale } \\
\text { (Brewer, Cornelius) (2) }\end{array}$ \\
\hline Expectations & 1 paper $(0.4 \%)$ & California Psychological Inventory \\
\hline $\begin{array}{l}\text { Life } \\
\text { satisfaction }\end{array}$ & 2 papers $(0.9 \%)$ & $\begin{array}{l}\text { Life Satisfaction-9 Questionnaire (Fugl } \\
\text { Meyer) (2) }\end{array}$ \\
\hline
\end{tabular}

assessment. We did not identify any study in which tools of activity measurement in SCI population such as Functional Independent Measure, Spinal Cord Indepenedence Measure or Walking Index of Spinal Cord Injury were used.

Environmental factors were described in 34 papers (15.2\%). Analyzed parameters included: place of living (17 papers), economic conditions ( 9 papers), health services ( 9 papers), assistive technologies (6 papers), family ( 7 papers), attitudes ( 5 papers), legal environment (3 papers), friends (3 studies), fulfillment of nutritional demands
( 1 study). Tools applied to assess environmental factors were mostly study-specific non-standardized questionnaires (Table 3).

Personal factors were assessed in 105 papers (46.9\%). Collected data included age (102 papers), gender (50 papers), education level (16 papers), marital status (13 papers), lifestyle such as physical activity or smoking (6 papers), awareness such as health awareness or awareness of disabled person's concerning their rights or privileges (5 papers), personality traits (5 papers) and self-acceptance ( 3 papers) Other studies assessed coping strategies, life purpose, motivation, athletic identity, expectations, desires, life satisfaction and social adaptation. Assessment tools were different across the studies and included Neuroliguistic Test of Problem Solving, Life Satisfaction-9 Questionnaire (Fugl Meyer), Athletic Identity Measurement scale (Brewer, Cornelius), Psychosocial Questionnaire for Spinal Cord Injured Persons, Adjective Checklist (Gough, Heilburn), Situational Preference Inventory (Edwards), Psychosocial Adjustment to Chronic Illness Questionnaire (Shontz, Fink), Purpose in Life Test (Crumbaugh, Macholik), Rotter incomplete sentences blank, Eysenck inventory and California Psychological Inventory (Table 4).

\section{DISCUSSION}

Systematic assessment of papers according to modified Downs and Black criteria revealed an explicit lack of overall quality, particularly in terms of power and internal validity of the studies. It should be emphasized that majority of the publications were published more than 20 years ago (Figure 1), and prepared according to methodological and reporting standard (if any) of that time.

We have identified, summarized and critically reviewed the available epidemiologic data on SCI in Poland. Our results suggest that the available epidemiologic data are either outdated or incomplete and biased toward capturing the biomedical and direct consequences of the injury rather than the impact of SCI on the individual's functioning level. Incidence of SCI in Poland remains to be uncertain and need more investigation due to reporting inconsistencies. Apart from incidental studies, there is no data concerning SCI of nontraumatic origin.

Outcomes of comprehensive care in acute and sub-acute stages of SCI between 1965 and 1993 have been described in multiple dimensions in 89 papers from STOCER. The main limitation of these studies is their focus on a single center, as well as application of exclusively locally developed diagnostic and assessment tools, rather than those used as 'standard' measurement instruments in other countries. Therefore, the data is probably representative only for eastcentral Poland (the region covered by STOCER). Forty-nine reports from other centers describing outcomes in acute and post-acute phase of SCI included lower number of participants (5-511, mean 80.1) and are mostly limited to analysis of a surgical outcome. Nevertheless, studies by the team of Weiss and Kiwerski can serve as a valuable basis for further epidemiologic studies. ${ }^{23,33-39}$

Most of the hospital-based studies focus on biomedical aspects of SCI. Data on functioning, when provided, concentrated mainly on mobility despite the fact that functioning involves multiple systems and multiple domains around activities of daily living. There are few studies on hand and respiratory functions of persons in the early period after SCI. Systematic studies concerning functioning of sensory, cardiovascular, urological or gastrointestinal systems are virtually nonexistent.

Studies looking at the environment fail to provide data that allow insight in SCI-related disability in Poland or the impact of the environment on SCI-related disability. Studies based on associations of persons with disabilities do not provide data for the SCI 
population, as it is unclear to what extent these associations cover the SCI population in Poland. Studies based on hospital records are characterized by a high dropout rate (reaching up to $22-42 \%$ ), especially if a long follow-up period is expected. The need for environment-based programs enabling functioning or participation in everyday life cannot be assessed properly without a prospective cohort study based on hospital records. Limitations of most of studies addressing environmental factors include a small number of participants, are not representative of the SCI population and apply different measurement tools. There is a lack of data that address long-term care results, the extent the health-care system fulfills the needs of persons with long-term SCI and the bio-psycho-social, economic and vocational situation of persons with SCI who are not involved in organizations for persons with disabilities. To address the abovementioned limitations and data quality issues, we believe that a National Register of SCI should be organized in Poland that would become the data platform for collecting epidemiologic data and initiation of cohort studies. More precise knowledge of bio-psychosocial needs of persons in various time points after SCI is essential for improving health and social care and for more effective interactions between health-care providers and administration bodies responsible for reimbursement, as well as to facilitate the social integration of persons with SCI. This data would also allow us to improve strategies to prevent and manage SCI in Poland.

Several longitudinal cohort projects collecting data on SCI have been conducted since the 1970s. Large studies such as Spinal Cord Injury Model System, ${ }^{41}$ European Multicenter Study About Spinal Cord Injury, ${ }^{42}$ Restoration of Mobility in SCI Rehabilitation: the Umbrella Project from Netherlands ${ }^{43}$ and Australian Spinal Cord Injury Register ${ }^{44}$ failed to comprehensively cover functional aspects determined in the Brief ICF Core Set for SCI. ${ }^{45}$ One large epidemiologic study that looks at SCI from a comprehensive perspective is the Swiss Spinal Cord Injury Study (SwiSCI). ${ }^{27}$ It is focused on understanding and improving the living experience of persons with SCI from the moment of injury to reintegration into society, with consideration of other long-term conditions including ageing. SwiSCI aims to accumulate evidence for better understanding of functioning, health maintenance, and quality of life of persons with SCI along the continuum of care, in the community and along their life span.

A similar strategy can be implemented in Poland to address the lack of a comprehensive and ICF-based broad data collection that would inform and facilitate treatment, care and rehabilitation of persons with SCI. Methodological issues, including the transferability of the SwiSCI design to Poland and the necessary modifications specific to Poland have to be investigated further.

\section{CONCLUSION}

Current epidemiologic data on SCI in Poland are insufficient. This is a challenge to the delivery of the quality and continuity of care for individuals with SCI in Poland. There is a need to develop a longterm research strategy on SCI, which can be addressed by facilitating a comprehensive cohort study. SwiSCI can be used as a model to develop a similar initiative in Poland.

\section{DATA ARCHIVING}

There were no data to deposit.

\section{CONFLICT OF INTEREST}

The authors declare no conflict of interest.

\section{ACKNOWLEDGEMENTS}

We are grateful to Professor Gerold Stucki, Dr Martin Brinkhof and Dr Jan Reinhardt of the Swiss Paraplegic Research in Nottwil, Switzerland, Professor Jerzy Kiwerski from STOCER and Dr Wieslaw Rycerski from Upper Silesian Rehabilitation Centre Repty for their invaluable comments.

1 World Health Organisation, World Bank. World Report on Disability. WHO: Geneva, 2011.

2 United Nations General Assembly. Convention on the rights of persons with disabilities Resolution 61/106 2006

3 Francis K. Physiology and management of bladder and bowel continence following spinal cord injury. Ostomy Wound Manage 2007; 53: 18-27.

4 DeForge D, Blackmer J, Garritty C, Yazdi F, Cronin V, Barrowman N et al. Male erectile dysfunction following spinal cord injury: a systematic review. Spinal Cord 2005; 44: 465-473.

5 Lombardi G, Del Popolo G, Macchiarella A, Mencarini M, Celso M. Sexual rehabilitation in women with spinal cord injury: A critical review of the literature. Spinal Cord 2010; 48: 842-849.

6 Krassioukov A. Autonomic function following cervical spinal cord injury. Respir Physiol Neurobiol 2009; 169: 157-164.

7 Bauman WA, Spungen AM. Metabolic changes in persons after spinal cord injury. Phys Med Rehabil Clin N Am 2000; 11: 109-140.

8 Yilmaz B, Yasar E, Goktepe AS, Onder ME, Alaca R, Yazicioglu K et al. The relationship between basal metabolic rate and femur bone mineral density in men with traumatic spinal cord injury. Arch Phys Med Rehabil 2007; 88: 758-761.

9 Gelis A, Dupeyron A, Legros P, Benaïm C, Pelissier J, Fattal C. Pressure ulcer risk factors in persons with SCI: Part I: Acute and rehabilitation stages. Spinal Cord 2009; 47: 99-107.

10 Gelis A, Dupeyron A, Legros P, Benaïm C, Pelissier J, Fattal C. Pressure ulcer risk factors in persons with spinal cord injury. Part 2: The chronic stage. Spinal Cord 2009; 47: 651-661.

11 Wahman K, Nash MS, Westgren N, Lewis JE, Seiger A, Levi R. Cardiovascular disease risk factors in persons with paraplegia: The Stockholm spinal cord injury study. $J$ Rehabil Med 2010; 42: 272-278.

12 Siddall PJ, Finnerup NB.. Pain following spinal cord injury. In: Handbook of Clinical Neurology (eds Vinken PJ and Bruyn GW) (Elsevier/North-Holland Biomedical Press: Amsterdam, 2006), pp 689-703.

13 Adams MM, Hicks AL. Spasticity after spinal cord injury. Spinal Cord 2005; 43 : $577-586$.

14 Lidal IB, Veenstra M, Hjeltnes N, Biering-Sørensen F. Health related quality of life in persons with long-standing spinal cord injury. Spinal Cord 2008; 46: 710-715.

15 Liu CW, Huang CC, Yang YH, Chen SC, Weng MC, Huang MH. Relationship between neurogenic bowel dysfunction and health related quality of life in persons with spinal cord injury. J Rehabil Med 2009; 41: 35-40.

16 Craig A, Tran Y, Middleton J. Psychological morbidity and spinal cord injury: A systematic review. Spinal Cord 2009; 47: 108-114.

17 New PW, Jackson T. The costs and adverse events associated with hospitalization of patients with spinal cord injury in Victoria, Australia. Spine 2010; 35: 796-802.

18 Krause JS, Carter RE. Risk of mortality after spinal cord injury: relationship with social support, education, and income. Spinal Cord 2009; 47: 592-596.

19 Munce SE, Wodchis WP, Guilcher SJ, Couris CM, Verrier M, Fung K et al. Direct costs of adult traumatic spinal cord injury in Ontario. Spinal Cord 2013; 5: 64-69.

20 French DD, Campbell RR, Sabharwal S, Nelson AL, Palacios PA, Gavin-Dreschnack D. Health care costs for patients with chronic spinal cord injury in the Veterans Health Administration. J Spinal Cord Med 2007; 30: 477-481.

21 Donovan HW. Spinal cord injury — past, present, and future. J Spinal Cord Med 2007; 30: $85-100$

22 Ullrich PM, Spungen AM, Atkinson D, Bombardier C H, Chen Y, Erosa NA et al. Activity and participation after spinal cord injury: State-of-the-art report. J Rehabil Res Dev 2012; 49: 155-174.

23 Kiwerski J. The causes, sequele and attempts at prevention of cervical spine injuries in Poland. Paraplegia 1993; 31: 527-533.

24 SPZOZ Repty Gornoslaskie Centrum Rehabilitacji (Accessed 19 September). Available from http://www.repty.pl/historia_gcr_repty, 1

25 Palak Z and Bartkowicz Z Wsparcie społeczne $w$ rehabilitacji $i$ resocjalizacji (eds UMCS: Lublin, 2007).

26 Foundation for Active Rehabilitation (Accessed 14 September 2012). Available from http://www.far.org.pl/select-your-language/english.html

27 Post MWM, Brinkhof MWG, von Elm E, Boldt C, Brach M, Fekete C et al. for the SwiSCI study group. Design of the Swiss Spinal Cord Injury Cohort Study. Am J Phys Med Rehabil 2011; 90 (11 Suppl 2), S5-S16.

28 Downs SH, Black N. The feasibility of creating a checklist for the assessment of the methodological quality both of randomised and non-randomised studies of health care interventions. J Epidemiol Community Health 1998; 52: 377-384.

29 Quality Assessment Tool and Data Extraction. (Accessed 31 October 2012). Available from http://www.scireproject.com/about-scire/methods-of-systematic-review/ article-assessment/quality-assessment-tool-and-data-extract 
30 World Health Organisation. International Classification of Functioning, Disability and Health: ICF. WHO: Geneva, 2001.

31 Pietraszkiewicz F, Tysiewicz-Dudek M. Epidemiology of spinal injuries in Lubuskie province in Poland. Ortop Traumatol Rehabil 2010; 12: 435-442.

32 Haftek I, Garlicki J, Tomczak M, Brzezińska B, Kowalczyk P. Epidemiologia urazów kręgosłupa i rdzenia kręgowego. Doniesienie wstępne. Kwart Ortop 2000, (Suppl) 11-18.

33 Kiwerski J, Ahmad SH. Paraplegia in women. Paraplegia 1983; 21: 161-165.

34 Kiwerski JE. Comparison of epidemiology, methods and results of treatment in cervical spinal injuries over the last 20 years in Poland. Eur Spine J 1993; 2: $165-168$.

35 Kiwerski J. The influence of the mechanism of cervical spine injury on the degree of the spinal cord lesion. Paraplegia 1991; 29: 531-536.

36 Kiwerski JE. Injuries to the spinal cord in elderly patients. Injury 1992; 23: 397-400.

37 Kiwerski J. Neurological improvement in traumatic injuries of the cervical spinal cord. Paraplegia 1981; 19: 31-37.

38 Kiwerski JE. Factors contributing to the increased threat to life following spinal cord injury. Paraplegia 1993; 31: 793-799.
39 Kiwerski J. Marked neurological improvement in patients after spinal cord injury in the cervical part hospitalized with tetraplegia. Chir Narz Ruchu 1983; 48: 263-268.

40 Tederko P, Czech J, Kiwerski J, Lauge I, Krasuski M. International Standards for Neurological Classification of Spinal Cord Injury in clinical practice - analysis of repeatability. Fizjoter Pol 2010; 3: 193-201.

41 Stover SL, DeVivo MJ, Go BK. History, implementation, and current status of the National Spinal Cord Injury Database. Arch Phys Med Rehabil 1999; 80: 1365-1371.

42 Curt A, Schwab ME, Dietz V. Providing the clinical basis for new interventional therapies: Refined diagnosis and assessment of recovery after spinal cord injury. Spinal Cord 2004; 42: 1-6.

43 de Groot S, Dallmeijer AJ, Post MW, van Asbeck FW, Nene AV, Angenot EL et al. Demographics of the Dutch multicenter prospective cohort study 'Restoration of mobility in spinal cord injury rehabilitation. Spinal Cord 2006; 44: 668-675.

44 O'Connor PJ. Trends in spinal cord injury. Accid Anal Prev 2006; 38: 71-77.

45 Eriks-Hoogland I, Cieza A, Post M, Hilfiker R, van Hedel H, Cripps R et al. Category specification and measurement instruments in large spinal cord injury studies: a comparison using the International Classification of Functioning, Disability, and Health as a reference. Am J Phys Med Rehabil 2011; 90 (11 Suppl 2), S39-S49.

Supplementary Information accompanies this paper on the Spinal Cord website (http://www.nature.com/sc) 